\title{
Determining the residual resource of the hammer crushers' rotor bearings
}

\author{
Nail R. Adigamov ${ }^{1, *}$, Rafis R. Shaikhutdinov ${ }^{1}$, Ildus H. Gimaltdinov ${ }^{1}$, Rishat R. Akhmetzyanov ${ }^{1}$, and Rafik S. Basyrov ${ }^{2}$ \\ ${ }^{1}$ Kazan State Agrarian University, 420015 Kazan, Russia \\ ${ }^{2}$ Kazan National Research Technical University named after A.N. Tupolev, 420111 Kazan, Russia
}

\begin{abstract}
The practice of operating machinery and equipment that are used in animal husbandry and in the processing of its products has shown low reliability of feed crushers. As of 01.01.2019, in the agricultural enterprises of the Republic of Tatarstan there are about 1200 machines for grinding feed, of which 800 pcs. are hammer crushers. Most of these crushers have a service life of 10 to 13 years and are objects with low reliability. Mostly emergency stops occur due to the destruction of the rotor bearings. In the event of a sudden failure, unplanned repairs and a decrease in production efficiency occur. At the Department of Operation and Repair of Machines of Kazan State Agrarian University, research was carried out and a scientific result was obtained, which was implemented in the adapter to the vibrometer to determine the residual life of rolling bearings. Input data for this device were obtained during operational research and further analysis of the data.
\end{abstract}

\section{Introduction}

Currently, in order to increase production and product quality and reduce its cost, it is necessary to introduce modern technology [1]. In the operation of machinery and equipment, timely and accurate determination of the technical condition and prediction of the residual life in order to conduct rational maintenance and repair is important. Research materials in this field are reflected in works [2-8]. So, most often, the object fails due to the destruction of the bearing. The results of the study in the field of determining the technical condition of the rotor bearings of hammer feed crushers are reflected in works $[9,10]$. As a result of these studies, a device was developed for determining the residual life, the input parameters for which were determined during laboratory and operational studies.

\section{Conditions, materials and research methods}

To analyze the effect of radial clearance in rolling bearings on vibration parameters, a laboratory setup was assembled at the Department of Machine Operation and Repair, shown in Figure 1.

At this installation, calibration studies were performed. Bearings with various degrees of wear were alternately mounted on the rotor and vibration parameters were fixed. Information was taken by a piezoelectric sensor. The signal was processed using a VVM-201 vibrometer, which is part of the diagnostic complex we developed.
Figure 2 shows a block diagram of the operation of a diagnostic complex for monitoring the technical condition of bearings and determining their residual life.

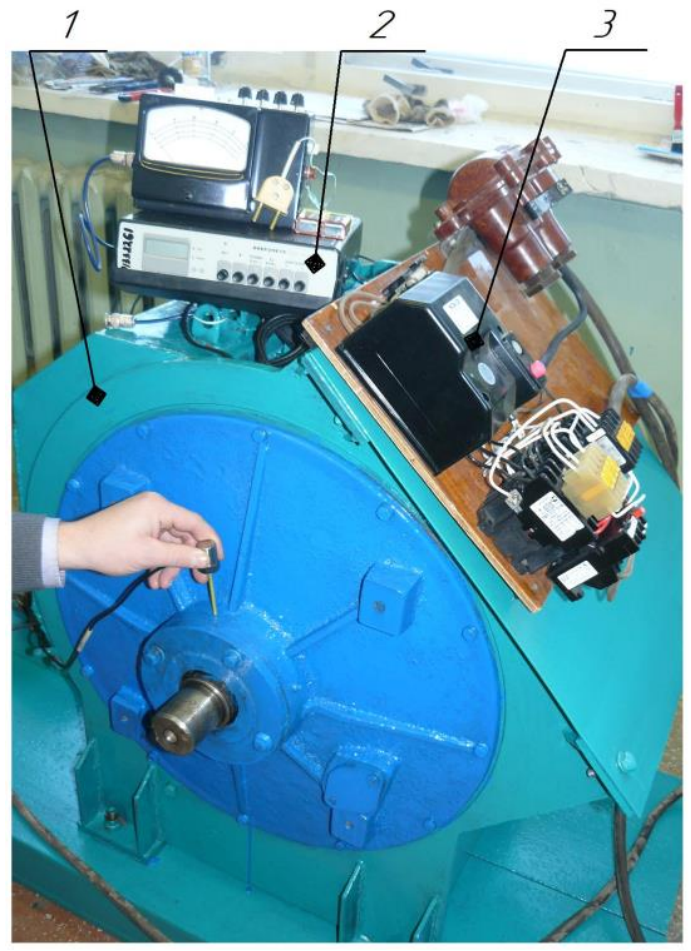

Fig. 1. Installation for laboratory research based on the feed crusher KD-2: 1 - crushing chamber; 2 - diagnostic complex; 3 - electric motor control panel

The proposed diagnostic complex works as follows. Vibrational jitters of the bearing unit are received by a piezoelectric type vibration sensor 1 , then this signal is fed to the input of the vibrometer 2 , where it is

* Corresponding author: n-adigamov@ rambler.ru 
converted, and in the form of a signal of vibration velocity or vibration acceleration through the detector 3 is fed to the input of the residual life attachment. In the adapter of the residual resource, the signal is amplified, analyzed, recorded and displayed on the dial indicator 8 , the deviation of which characterizes the data on the actual state and residual resource. The deviations of the dial indicator also depend on the input parameters set by the operator using the controls. This is information about wear rate and total resource.

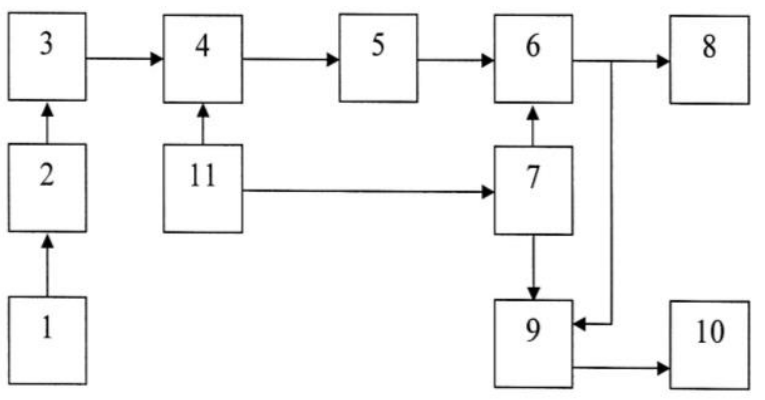

Fig. 2. Block diagram of the diagnostic complex: 1 piezoelectric type vibration sensor; $2-$ VVM-201 vibrometer; 3 - detector; 4 - voltage divider No. 1; 5 - amplifier of the 1st stage; 6 - summing amplifier; 7 - voltage divider No. 2; 8 arrow indicator; 9 - a device comparing; 10 - sound alarm unit; 11 is a voltage stabilizing block.

The adapter for determining the residual life has an error of $3 \%$, a vibrometer - of $2 \%$. A general view of the diagnostic complex is shown in Figure 3.

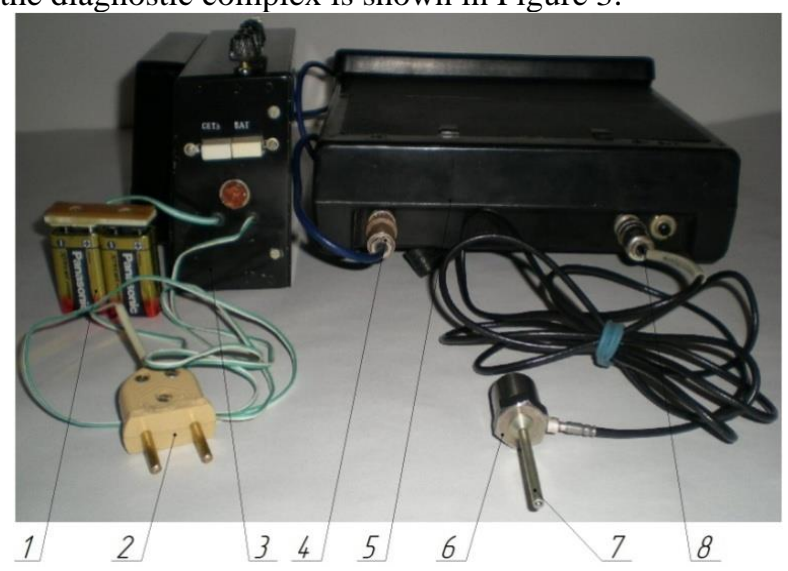

Fig. 3. General view of the diagnostic complex to determine the residual life of the bearing assemblies: 1 - autonomous power supply; $2-220 \mathrm{~V}$ power plug; 3 - adapter for determining the residual resource; 4 - output channel of the vibrometer; 5 - VVM-201 vibrometer; 6 - piezoelectric vibration sensor; 7 - manual probe; 8 - input channel of the vibrometer.

Operational research was carried out directly at the agricultural enterprises of the Republic of Tatarstan [10], such as "Abdreev's agricultural enterprise Shaimurzinsky", Drozhzhanovsky district; OJSC "Kiyatskoe", Buinsky district,; agricultural production "Ural", Kukmorsky district, and others.

\section{Results of the study}

In laboratory studies of the vibration dependence parameters on the degree of wear of rolling bearings, the following results were obtained, presented in table 1 and 2 .

Table 1. Measured values of the vibration velocity of the bearings on the drive side

\begin{tabular}{|c|c|c|c|c|c|}
\hline$z .2$ & $z 1$ & & & & \\
\hline 0.03 & 32.03 & 34.94 & 37.78 & 40.70 & 44.26 \\
\hline 0.08 & 32.74 & 35.65 & 38.19 & 41.50 & 45.08 \\
\hline 0.13 & 33.46 & 36.43 & 39.04 & 42.32 & 45.26 \\
\hline 0.2 & 34.54 & 37.33 & 40.08 & 43.31 & 47.07 \\
\hline 0.27 & 35.34 & 38.53 & 40.93 & 45.45 & 47.91 \\
\hline
\end{tabular}

Table 2. The measured values of the vibration velocity of the bearings on the fan side

\begin{tabular}{|c|c|c|c|c|c|}
\hline$z .2$ & & & & & \\
\hline 0.03 & 15.10 & 15.66 & 15.94 & 16.62 & 17.4 \\
\hline 0.08 & 16.12 & 17.77 & 18.02 & 18.964 & 20.00 \\
\hline 0.13 & 16.66 & 20.40 & 20.87 & 21.88 & 23.07 \\
\hline 0.2 & 24.18 & 24.25 & 24.5 & 25.9 & 26.68 \\
\hline 0.27 & 27.86 & 28.16 & 28.05 & 29.47 & 31.09 \\
\hline
\end{tabular}

According to the data obtained, an increase in the radial clearance in the bearings leads to an increase in the level of vibration velocity and is linear.

In order to confirm the adequacy of the results of laboratory experiments, operational studies were conducted at agricultural enterprises of the Republic of Tatarstan.

The results of operational studies of the dependence of the radial clearance of bearings of feed crushers on operating hours are shown in Figures 4 and 5.

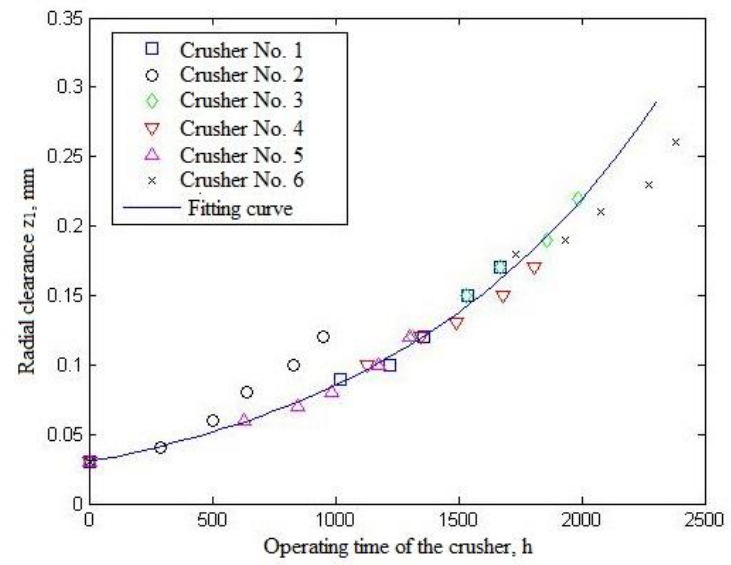

Fig. 4. Radial clearance in the feed crusher bearings on the drive side, depending on the operating time.

The feed crusher bearing No. 2 on the drive side showed an atypical, for the other crushers, high wear rate, which is possibly due to a manufacturing defect in a bearing. When constructing a regression curve, the data of this bearing were not considered. 


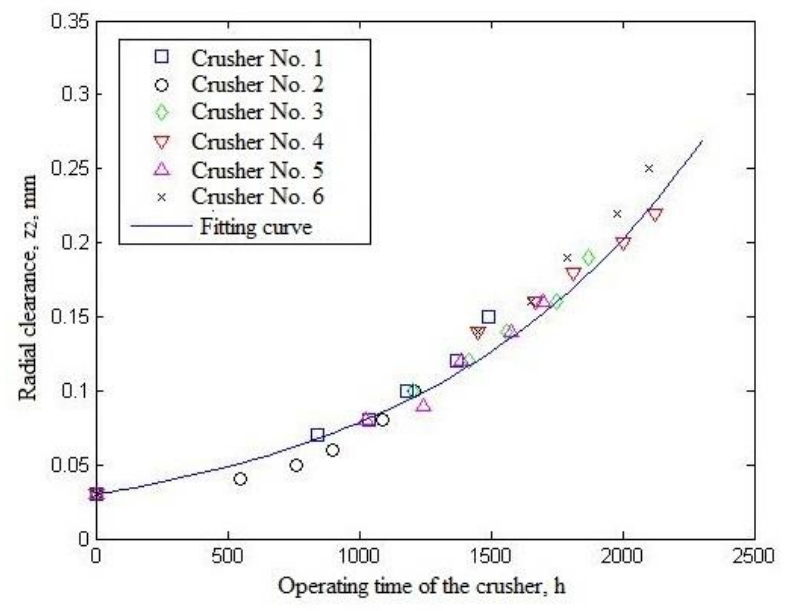

Fig. 5. Radial clearance in the feed crusher bearings on the fan side, depending on the operating time.

From Figures 4 and 5, it can be stated that the average operating time of the rotor bearings of the hammer crusher KD-2 until the pre-failure condition occurs on the drive side is from 800-900 hours, and from the fan side 1200-1300 hours.

Assuming the exponential nature of the radial bearing dependences clearance on the running hours, the regression curves were determined using the following formulas:

$$
\begin{aligned}
& z_{1}=z_{0}+C_{1}\left(e^{\beta_{1} t}-1\right), \\
& z_{2}=z_{0}+C_{2}\left(e^{\beta_{2} t}-1\right) .
\end{aligned}
$$

where $\mathrm{z}_{0}$ is the radial clearance in the new bearing.

Bearings 3610 with a nominal radial clearance of $\mathrm{z}_{0}=0.03 \mathrm{~mm}$ are mounted on the rotor of the most common feed crushers KD-2, KDU-2, DB-5.

The coefficients $C 1, C 2, \beta 1$, and $\beta 2$ were obtained using the least-squares smoothing function of experimental data in MATLAB. As a result of processing the data obtained during the tests, the following numerical values were obtained:

$$
\begin{aligned}
& \mathrm{C}_{1}=0.039 \mathrm{~mm}, \beta_{1}=8.84 \cdot 10^{-4} 1 / \text { hour, } \\
& \mathrm{C}_{2}=0.031 \mathrm{~mm}, \beta_{1}=9.42 \cdot 10^{-4} 1 / \text { hour. }
\end{aligned}
$$

Using dependencies (1) and (2), based on the information on the radial clearance value, one can find the actual operating time of feed crushers by the expressions:

$$
\begin{aligned}
& T_{1 \text { fact }}=\frac{1}{\beta_{1}} \ln \left(\frac{z_{1 \text { fact }}-z_{0}}{C_{1}}+1\right), \\
& T_{2 \text { fact }}=\frac{1}{\beta_{2}} \ln \left(\frac{z_{2 \text { fact }}-z_{0}}{C_{2}}+1\right) .
\end{aligned}
$$

The total operating time to achieve the maximum radial clearance of a bearing can be calculated by the formulas:

$$
\begin{gathered}
T_{1 \text { full }}=\frac{1}{\beta_{1}} \ln \left(\frac{z_{b}-z_{0}}{C_{1}}+1\right) ; \\
T_{2 \text { full }}=\frac{1}{\beta_{2}} \ln \left(\frac{z_{b}-z_{0}}{C_{2}}+1\right) .
\end{gathered}
$$

The remaining bearing life is defined as the difference

$$
T_{\text {left }}=T_{\text {full }}-T_{\text {fact }} .
$$

The current values of the radial clearances can be determined based on the measured values of the vibration velocity parameters from the expressions [9].

\begin{tabular}{|c|c|c|c|c|c|c|c|c|c|}
\hline $\mathrm{V}_{2}$ & 32 & 34 & 36 & 38 & 40 & 42 & 44 & 46 & 48 \\
\hline 1 & 2 & 3 & 4 & 5 & 6 & 7 & 8 & 9 & 10 \\
\hline \multirow[t]{2}{*}{15} & 0.0348 & 0.0580 & 0.1013 & & & & & & \\
\hline & 0.0590 & 0.0477 & 0.0365 & & & & & & \\
\hline \multirow[t]{2}{*}{17} & & 0.0468 & 0.0900 & 0.1333 & 0.1765 & 0.2197 & 0.2630 & & \\
\hline & & 0.0856 & 0.0743 & 0.0631 & 0.0518 & 0.0406 & 0.0293 & & \\
\hline \multirow[t]{2}{*}{19} & & 0.0355 & 0.0788 & 0.1220 & 0.1653 & 0.2085 & 0.2517 & 0.2950 & 0.3382 \\
\hline & & 0.1234 & 0.1122 & 0.1009 & 0.0897 & 0.0784 & 0.0672 & 0.0559 & 0.0447 \\
\hline \multirow[t]{2}{*}{21} & & & 0.0675 & 0.1108 & 0.1540 & 0.1972 & 0.2405 & 0.2837 & 0.3270 \\
\hline & & & 0.1500 & 0.1387 & 0.1275 & 0.1162 & 0.1050 & 0.0938 & 0.0825 \\
\hline \multirow[t]{2}{*}{23} & & & 0.0563 & 0.0995 & 0.1428 & 0.1860 & 0.2292 & 0.2725 & 0.3157 \\
\hline & & & 0.1878 & 0.1766 & 0.1653 & 0.1541 & 0.1428 & 0.1316 & 0.1203 \\
\hline \multirow[t]{2}{*}{25} & & & 0.0450 & 0.0883 & 0.1315 & 0.1748 & 0.2180 & 0.2612 & 0.3045 \\
\hline & & & 0.2256 & 0.2144 & 0.2031 & 0.1919 & 0.1807 & 0.1694 & 0.1582 \\
\hline \multirow[t]{2}{*}{27} & & & 0.0338 & 0.0770 & 0.1203 & 0.1635 & 0.2068 & 0.2500 & 0.2932 \\
\hline & & & 0.2635 & 0.2522 & 0.2410 & 0.2297 & 0.2185 & 0.2072 & 0.1960 \\
\hline \multirow[t]{2}{*}{29} & & & & 0.0658 & 0.1090 & 0.1523 & 0.1955 & 0.2387 & 0.2820 \\
\hline & & & & 0.2900 & 0.2788 & 0.2676 & 0.2563 & 0.2451 & 0.2338 \\
\hline \multirow[t]{2}{*}{31} & & & & 0.0546 & 0.0978 & 0.1410 & 0.1843 & 0.2275 & 0.2707 \\
\hline & & & & 0.3279 & 0.3166 & 0.3054 & 0.2941 & 0.2829 & 0.2717 \\
\hline
\end{tabular}

$$
\begin{aligned}
& z_{1}=0.0216 V_{1}-0.0056 V_{2}-0.5927, \\
& z_{2}=-0.0056 V_{1}+0.0189 V_{2}-0.0448,
\end{aligned}
$$

here $\mathrm{V}_{1}$ and $\mathrm{V}_{2}$ are the parameter of the vibration velocity of the bearing on the drive and fan sides, respectively, $\mathrm{z}_{1}$ and $\mathrm{z}_{2}$ are the clearance of the drive and fan bearings.

Table 3. Radial clearances calculated by formulas (1) and (2) 
Table 4. The calculated values for the expression (3) and (7)

\begin{tabular}{|c|c|c|c|c|c|c|c|c|c|c|c|}
\hline $\mathrm{Z}_{1}, \mathrm{~mm}$ & 0.05 & 0.07 & 0.09 & 0.11 & 0.13 & 0.15 & 0.17 & 0.19 & 0.21 & 0.23 & 0.25 \\
\hline $\mathrm{T}_{1}$ fact, hour & 468 & 799 & 1054 & 1262 & 1438 & 1590 & 1738 & 1844 & 1932 & 2051 & 2142 \\
\hline $\mathrm{T}_{1 \text { left, }}$ hour & 1758 & 1427 & 1172 & 964 & 788 & 636 & 502 & 382 & 274 & 175 & 84 \\
\hline $\mathrm{V}_{\text {wear, }} \mu \mathrm{m} /$ hour & 0.052 & 0.070 & 0.088 & 0.105 & 0.123 & 0.141 & 0.158 & 0.176 & 0.194 & 0.211 & 0.229 \\
\hline
\end{tabular}

Table 5. The calculated values for the expressions (4) and (7)

\begin{tabular}{|c|c|c|c|c|c|c|c|c|c|c|c|}
\hline $\mathrm{Z} 2, \mathrm{~mm}$ & 0.05 & 0.07 & 0.09 & 0.11 & 0.13 & 0.15 & 0.17 & 0.19 & 0.21 & 0.23 & 0.25 \\
\hline $\mathrm{T}_{\text {2fact }}$, hour & 529 & 880 & 1143 & 1354 & 1530 & 1680 & 1813 & 1930 & 2036 & 2132 & 2220 \\
\hline $\mathrm{T}_{\text {2left, hour }}$ & 1773 & 1422 & 1158 & 948 & 772 & 621 & 489 & 371 & 266 & 170 & 81 \\
\hline $\begin{array}{c}\mathrm{V}_{\text {wear }} \\
\mu \mathrm{m} / \text { hour }\end{array}$ & 0.048 & 0.067 & 0.086 & 0.105 & 0.123 & 0.142 & 0.161 & 0.180 & 0.199 & 0.218 & 0.236 \\
\hline
\end{tabular}

The clearances calculated by the formulas [9] are given in Table 3. The top row of the inner cells corresponds to $\mathrm{z}_{1}$, the bottom to $\mathrm{z}_{2}$. Since the vibration parameters of the drive and fan are not independent (there is a correlation between them), not all combinations of their values are possible. This is manifested in the fact that the gap values calculated using models [9] turn out to be less than $\mathrm{z}_{0}=0.03 \mathrm{~mm}$. In such cases, the cells in table 3 are left blank.

Tables 4 and 5 below show the current operating time, residual life and wear rate of the drive and fan bearings, depending on the radial clearance, calculated according to models (5), (6).

The numerical values obtained from models (5) and (6) were used when setting up the set-top box to determine the residual life.

\section{Conclusion}

As a result of laboratory experiments and operational studies at the agricultural enterprises, a linear dependence of the vibration parameter values in the bearing units of the KD-2 feed crushers on the radial clearance value was established. The dependence of the radial clearance on the operating time is exponential. An analysis of the data showed that the vibration velocity is the most informative, as having the smallest dispersion when checking the convergence of experimental and calculated data. It has been established that the average operating time of the rotor bearings of the hammer crusher KD-2 before the pre-failure condition on the drive side is from 800-900 hours, and on the fan side 1200-1300 hours. The calculation of the residual life of rolling bearings is based on the obtained analytical dependences of the vibration parameters, radial clearance and running hours.

The developed mobile diagnostic complex of rolling bearings allows you to determine their condition directly on the feed crusher without dismantling.

\section{References}

1. B.G. Ziganshin, R.R. Shaidullin, A.R. Valiev, A.B. Moskvicheva, F.F. Sitdikov, T. Heidenreich, Analysis of technical solutions in optimizing the conditions of dairy cattle during the construction and reconstruction of livestock farms, Bull. of Kazan State Agrar. Univer., 13(2(49)), 138-143 (2018)

2. I.G. Galiev, K.A. Khafizov, F.Kh. Khaliullin, Modernization of the lubrication system of the bearing assembly of a turbocompressor of a tractor engine, Bull. of Kazan State Agrar. Univer., 14(1(52)), 71-76 (2019)

3. I.G. Galiev, R.K. Khusainov, Results of determining the optimal values of the overhaul time between tractors in agricultural production, taking into account the level of their operation, Bull. of Kazan State Agrar. Univer., 11(2(40)), 87-90 (2016)

4. M.N. Kalimullin, R.K. Abdrakhmanov, A.S. Mikhailovich, Rotary haulm chopper parameters development and substantiation for root and tuber crops, Int. J. of Appl. Engineer. Res., 10(10), 25691-25698 (2015)

5. I.M. Zyabirov, V.A. Machnev, A.I. Zyabirov, Remote control of the parameters of the technical condition of the working units of combine harvesters, Niva Volga, 4(41), 75-79 (2016)

6. D.B. Vlasov, N. Mashrabov, A.M. Plaksin, D.D. Bakaykin, A.V. Gritsenko, Diagnostic technologies for electric gasoline pumps, Agroindustrial complex of Russia, 26(1), 51-55 (2019)

7. A.V. Gritsenko, N. Mashrabov, S.A. Baryshnikov, A.S. Balyasnikov, V.S. Savosin, Vibroacoustic control of the gas distribution mechanism of the internal combustion engine, Agroindustrial complex of Russia, 26(2), 203-215 (2019)

8. A.P. Inshakov, Yu.B. Fedotov, S.S. Desyayev, D.V. Baikov, The problem of monitoring and balancing the batteries of vehicles, Bull. of the Mordov. Univer., 26(1), 40-49 (2016)

9. N.R. Adigamov, I.H. Gimaltdinov, Theory and practice of determining the residual life of bearing assemblies of feed crushers, Machin. and equipm. for the village, 10, 44-48 (2015)

10. N.R. Adigamov, I.H. Gimaltdinov, Laboratory and operational tests of an in-place diagnosis installation for livestock farm equipment, Bull. of Kazan State Agrar. Univer., 6(2(20)), 89-90 (2011) 